\title{
Formic acid electrooxidation on thallium modified platinum single crystal electrodes.
}

J. V. Perales-Rondón ${ }^{b}$, C. Busó-Rogero ${ }^{b}$, J. Solla-Gullón $^{b}$, E. Herrero, ${ }^{a, b}$ and J. M.

$$
\text { Feliu }^{a, b} \text {. }
$$

${ }^{a}$ Departamento de Química-Física, Universidad de Alicante Apartado 99, E-03080, Alicante, Spain.

${ }^{b}$ Instituto de Electroquímica, Universidad de Alicante Apartado 99, E-03080, Alicante, Spain.

\begin{abstract}
Formic acid electrooxidation on $\mathrm{Tl}$ modified $\mathrm{Pt}$ single crystal electrodes has been carried out in sulfuric acid media. Voltammetric experiments demonstrated that $\operatorname{Pt}(100)$ modified by $\mathrm{Tl}$ displays a significant enhancement towards formic acid oxidation both lowering the oxidation onset potential and increasing the maximum current density in the positive going-sweep. A similar behavior has been observed in $\operatorname{Pt}(s)[(100) x(111)]$ stepped surfaces. On the other hand, for $\mathrm{Pt}(111)$ surfaces, the incorporation of $\mathrm{Tl}$ also induced a shift of the oxidation onset to lower potential values, a diminution of the hysteresis between the positive and negative going-sweep and also an increase of the oxidation currents. These results have been corroborated using in situ FTIR experiments, where the $\mathrm{CO}$ adsorption band disappears completely when $\operatorname{Pt}(100)$ and its vicinal surfaces are modified by $\mathrm{Tl}$ adatom, leading to the formation of $\mathrm{CO}_{2}$ at lower overvoltages.
\end{abstract}




\section{Introduction}

Formic acid oxidation is known to be a very important reaction in electrocatalysis $[1,2]$. It can be used as a model reaction for more complex organic molecules, given that i) its oxidation process only involves two electrons, ii) an additional oxygen atom is not required to produce $\mathrm{CO}_{2}$, and finally, iii) it is a clear example of a reaction sensitive to the surface structure of the electrocatalyst. In addition, formic acid has been proposed as a possible fuel for fuel cells with portables and small power applications [1, 3, 4]. Although this species emerges as a possible fuel in direct formic acid fuel cells (DFAFC), its application is limited by a low power density and the poisoning of the catalyst. Therefore, high active catalysts towards formic acid oxidation are required.

It is well accepted that formic acid oxidation reaction (FAOR) proceeds via two different routes in Pt electrodes: the so-called indirect pathway, where CO (poisoning intermediate) is formed in the electrode surface, being then oxidized to $\mathrm{CO}_{2}$ at high potentials; and the second route (direct pathway), which involves the formation of an active intermediate, presumably a formate weakly adsorbed species [5, 6], and its subsequent oxidation into $\mathrm{CO}_{2}$ at low potentials. This dual pathway mechanism sets one of the main problems to be solved in order to catalyze this reaction in Pt electrodes, which is suppressing the poison formation route and enhancing the oxidation through the direct pathway.

There are two classical approaches to enhance the activity of the electrocatalyst, namely, modifying the surface structure, or changing the composition of the electrode. The first one consists in preparing electrodes with different atomic arrangement, providing specific surface symmetry that favors the formic acid oxidation by the direct pathway $[7,8]$. The second one implies the modification of the platinum surfaces with 
the adsorption of foreign atoms. This second approach has been widely studied over the past years. Adatoms such as bismuth (Bi) [9], antimony (Sb) [10, 11], arsenic (As) [11] or palladium (Pd) [12] provide an important improvement in the catalytic activity, not only in terms of maximum current density, but also in shifting the oxidation onset potential to lower potential values. One reasons for this enhancement is the so-called, third body effect [13], in which one of the metals acts with a steric influence to suppress the poison formation, enhancing the activity through the other pathway. However, some of the adatoms promote also an important bifunctional effect [13-15], where the adatom act as a promotor of the active intermediate in a specific configuration, thus decreasing the activation energy of the process through the direct pathway. The case of $\mathrm{Bi}$ modification is a clear example of this bifunctional effect [16].

In recent years, an increasing interest has been set on those metals that have been less studied, among this, thallium adatom. In earlier studies, Clavilier et al. [17] perfomed the underpotential deposition (UPD) of $\mathrm{Tl}^{+}$on $\mathrm{Pt}(111)$ electrode, arguing that there is an equilibrium in the adsorption-desorption process. More recently, Rodriguez et al. [18] has studied extensively either the UPD and irreversible adsorption of $\mathrm{Tl}$ on $\operatorname{Pt}(111)$ and vicinal surfaces. They were able to ascribe the processes $\mathrm{Tl} / \mathrm{Tl}^{+}$oxidation and anion adsorption on the Tl-modified surface. Additionally, the results obtained with stepped surfaces indicate that some of the features are clearly associated to the presence of (111) surface domains (terraces).

On the other hand, some few works has studied the FAOR on $\mathrm{Tl}$ modified Pt electrodes. For instance, Hartung et al.[19] reported the effect of $\mathrm{Tl}$ deposition on $\mathrm{Pt}$ electrodes towards formic acid oxidation, concluding that $\mathrm{Tl}$ catalyse the direct oxidation of bulk $\mathrm{HCOOH}$. More recently, $\mathrm{Tl}$ modified shape-controlled $\mathrm{Pt}$ nanoparticles showed an important enhancement of the FAOR [20], concluding that 
preferentially (100) Pt nanoparticles (cubic shape) modified by Tl were more active than the (111) Pt nanoparticles (octahedral shape) in the entire range of $\mathrm{Tl}$ coverages. However, despite these previous contributions, a fundamental study dealing with the activity of Tl modified Pt single crystal electrodes have not been conducted yet. For that reason, in this contribution, an electrochemical and spectroscopic study of formic acid oxidation on Tl modified Pt single crystal electrodes, both using basal planes and stepped surfaces are presented.

\section{Experimental}

Platinum single crystal electrodes were oriented, cut and polished from small single crystal Pt beads (2.5 mm diameter) following the method developed by Clavilier et al.[21]. Before all the experiments, working electrodes were flame annealed during $30 \mathrm{~s}$, cooled down in a $\mathrm{H}_{2} / \mathrm{Ar}$ atmosphere and quenched in ultrapure water in equilibrium with this atmosphere before immersion in the electrochemical cell [22]. Tl deposition on Pt was performed by cycling between $0.06 \mathrm{~V}$ and $0.65 \mathrm{~V}$ for $\operatorname{Pt}(100)$ and $\operatorname{Pt}(s)[(100 x 111)]$ stepped surfaces, and between $0.06 \mathrm{~V}$ and $0.50 \mathrm{~V}$ for $\operatorname{Pt}(111)$ electrodes. The upper potential was chosen in order to preserve the surface order and also to avoid problems of $\mathrm{Tl}$ desorption at higher potentials. Diluted solutions of $\mathrm{Tl}^{+}$ $\left(\mathrm{Tl}_{2} \mathrm{SO}_{4}\right.$, Aldrich $\left.^{\circledR} 99.995 \%\right)$ with concentrations between $10^{-5} \sim 10^{-6} \mathrm{M}$ in $0.5 \mathrm{M} \mathrm{H}_{2} \mathrm{SO}_{4}$ were used.

Experiments were carried out at room temperature $\left(25^{\circ} \mathrm{C}\right)$, in a classical electrochemical cell, including a large platinum counter electrode and a reversible hydrogen (N50) electrode $(R H E)$ as reference. All potentials used in this work are

referred to RHE. The solutions were prepared by using $\mathrm{H}_{2} \mathrm{SO}_{4}$ (Merck KGaA Suprapur ${ }^{\circledR}$ 
96\%), formic acid (Merck KGaG $98 \%$ ) and ultrapure water (Elga PureLab Ultra 18.2 $\mathrm{M} \Omega \mathrm{cm}$ ), preparing $0.1 \mathrm{M} \mathrm{HCOOH}+0.5 \mathrm{M} \mathrm{H}_{2} \mathrm{SO}_{4}$ solution. Ar (N50, Air Liquide) was used for deoxygenating the solutions. All the electrochemical measurements (cyclic voltammetry) were performed using a waveform generator (EG\&G PARC 175) coupled to a potentiostat (eDAQ EA161) and a digital recorder (eDAQ ED401).

In situ FTIR measurements were performed in a Nicolet 8700 spectrometer equipped with a mercury cadmium telluride (MCT) detector, according with the external reflection configuration for a transparent prism of $\mathrm{CaF}_{2}$ beveled at $60^{\circ}$ [23] and coupled with the spectroelectrochemical cell. For each spectrum, 100 interferograms were averaged to increase the signal-to-noise ratio, using a resolution of $8 \mathrm{~cm}^{-1}$. For all the experiments, $p$-polarized light was used, allowing the detection of species adsorbed on the electrode surface and other species in the electrolyte solution. Spectra were presented in absorbance units, $A=-\log \left(R_{1}-R_{2}\right) / R_{1}$, in which $R_{1}$ and $R_{2}$ are the reflectance values for the single-beam spectra recorded at the sample and the reference potential respectively. Positive bands in spectra are related to species formed at the sampling potential with respect to the reference potential, whereas negative bands correspond to species consumed. IR spectra were collected at intervals of $50 \mathrm{mV}$ between $0.05 \mathrm{~V}$ and $0.5 \mathrm{~V}$, and $100 \mathrm{mV}$ between $0.5 \mathrm{~V}$ and $0.9 \mathrm{~V}$ vs. RHE. Spectrum taken at $0.05 \mathrm{~V}$ was used as a reference in all spectra presented.

\section{Results and discussion}

\subsection{FAOR on Tl modified Pt(100) and Pt(111) electrodes}

Figure 1 shows the voltammetric profiles corresponding to a) $\operatorname{Pt}(100)$ and $b$ ) $\mathrm{Pt}(111)$ modified with $\mathrm{Tl}$ at different coverages in $0.5 \mathrm{M} \mathrm{H}_{2} \mathrm{SO}_{4}$. In the case of $\mathrm{Pt}(100)$, 
two different regions can be distinguished. The first one, located between $0.06 \mathrm{~V}$ and $0.20 \mathrm{~V}$, where a new peak centered at $0.17 \mathrm{~V}$ appears for increasing thallium coverages and a second one involving the decrease of the contributions from $0.2 \mathrm{~V}$ to $0.5 \mathrm{~V}$, related to the competitive adsorption between hydrogen and sulfate anions on the $\mathrm{Pt}$ surface. In order to find out the nature of the peak at $0.17 \mathrm{~V}$, the peak potential position (in the hydrogen electrode scale (SHE)) was plotted against solution $\mathrm{pH}$ (figure 2). A slope value of $52 \mathrm{mV}$ was obtained, very near to $59 \mathrm{mV}$, which implies that one proton is exchanged per electron in the surface redox reaction. Since the charge of this process is small and the peak is only well defined at high coverages, it can be proposed that the reaction is associated to the hydrogen adsorption process on a Pt site surrounded by $\mathrm{Tl}$ adatoms. Thus, considering $\mathrm{Tl}$ as an electropositive adatom, this finding suggests that its presence modifies the adsorption of hydrogen profile, lowering the potential where the adsorption starts to occur.

On the other hand, for $\operatorname{Pt}(111)$, there is a clear decrease of the voltammetric profile comparing to the blank, both the hydrogen adsorption/desorption region and the anion adsorption/desorption regions [17]. However, a new peak around $0.48 \mathrm{~V}$ appears very close to the spike in the unmodified surfaces. This sharp spike is related to the order disorder transition in the sulfate layer $[17,18,24]$. Thus, it can be proposed that $\mathrm{Tl}$ is modifying the energetics of this order-disorder transition. Moreover, an additional prove for that can be obtained when the voltammetric profiles in the absence and presence of sulfate. Figure 3 displays the appearance of a new small peak around $0.48-0.50 \mathrm{~V}$ for a Tl modified Pt(111) after adding small amounts of sulfate into a perchloric acid solution. This result suggests that the peak at $0.48 \mathrm{~V}$ is related to the rearrangement of the sulfate layer adsorbed on the $\mathrm{Tl}$ modified $\mathrm{Pt}$ surface. The latter result was 
demonstrated by Rodriguez et al. by the observation of the displacement of this peak when changing the sulfate concentration in the solution at a constant $\mathrm{pH}$ [18].

The results shown in figure 1 can be also use to monitor the deposition of $\mathrm{Tl}$ adatom, by the decreasing of the currents in the main region related to hydrogen and anion adsorption desorption, as previously done in a former work [20]. Thus, since T1 coverage could be followed through the decreasing of the hydrogen adsorption/desorption region at each $\mathrm{Pt}$ electrode profile, the $\mathrm{Tl}$ coverage could be calculated by using the following equation:

$$
\theta_{T l}=1-\theta_{\mathrm{H}}=\frac{q_{H}^{0}-q_{H}^{T l}}{q_{H}^{0}}
$$

where $q_{H}^{0}$ and $q_{H}^{T l}$ are the hydrogen adsorption charges of the clean and thallium modified electrodes respectively, calculated after the subtraction of the double layer charging contribution. This equation have been extensively used in the calculation of coverage of a large number of adatoms [2], considering that an adatom can blocked a specific number of $\mathrm{Pt}$ sites where hydrogen adsorption takes place. For $\mathrm{Pt}(100)$ the coverage was calculated between 0.22 and $0.50 \mathrm{~V}$, whereas for $\operatorname{Pt}(111)$ the potential limits were set between 0.06 and $0.325 \mathrm{~V}$ in order to avoid some contribution coming from signals belonging to $\mathrm{Tl}$ redox surface processes.

Both $\mathrm{Tl}$ modified electrodes were used to study FAOR. Figure $4 \mathrm{a}$ and $\mathrm{b}$ show the formic acid oxidation activity as a function of the $\mathrm{Tl}$ coverage (only positive going sweeps are shown). For the $\operatorname{Pt}(100)$ electrode, the activity in the positive sweep is almost zero (black line), due to the important poisoning of the electrode by $\mathrm{CO}$ that takes place between 0.25 and $0.4 \mathrm{~V}$, widely documented in previous works [1, 25]. The first effect of the $\mathrm{Tl}$ modification is the evident diminution of the onset potential of the 
oxidation, which starts at about $0.15 \mathrm{~V}$ for intermediate coverages. In addition, a clear increase of the current density for the FAOR is observed showing a peak at about 0.5 $\mathrm{V}$. Interestingly, the current density grows as the $\mathrm{Tl}$ coverage increase, reaching a maximum value at $\theta_{T l} \cong 0.33$ (small coverage values). From this coverage, the current density decreases, although the onset potential remains similar to that obtained for $\theta_{T l} \cong 0.33$. Finally, at the maximum coverage studied $\left(\theta_{T l} \cong 0.78\right)$, a significant decrease of the current and a shift of the onset potential to more positive values are observed. This fact indicates that the presence of $\mathrm{Tl}$ at high coverages has a negative effect, presumably due to the blockage of a large number of Pt sites to achieve the oxidation of formic acid. The last observation is in agreement with the actuation mechnanisms of the adatomos proposed in [13]. Thus, with increasing amounts of $\mathrm{Tl}$ until a maximum value ca. $\theta_{T l} \cong 0.30$, the indirect pathway (through $\mathrm{CO}$ poisoning) is hindered, promoting formic acid oxidation through the direct pathway.

Figure $4 \mathrm{~b}$ shows the results obtained with a $\mathrm{Pt}(111)$ surface. The results also suggest that the incorporation of $\mathrm{Tl}$ have a positive effect in the activity of the electrode, specially, increasing the current density of the oxidation in the low potential region. Also a shift in the onset potential of the oxidation can be achieved. For low coverages $\left(\theta_{T l} \approx 0.10\right)$, the improvement in the activity is less significant, being similar at high coverages $\left(\theta_{T l} \approx 0.82\right)$. Nevertheless, the main effect is achieved at medium-high coverages, i.e. $\theta_{T l} \approx 0.70$. In fact, at $\theta_{T l} \approx 0.76$, the current density reach maximum values $\left(7 \mathrm{~mA} \cdot \mathrm{cm}^{-2}\right)$. In the voltammetric profile can be seem that the current starts to increases at potential as low as $0.15 \mathrm{~V}$, reaching the highest activity at $0.4 \mathrm{~V}$. In this case, it is clear that $\mathrm{Tl}$ has a positive effect for the FAOR. For adatoms, such as $\mathrm{Tl}$, which are electropositive with respect to Pt, the catalytic effect has been explained using a bifunctional mechanism, in which the adatom facilitate the adsorption of formate in 
the right position, so that the $\mathrm{C}-\mathrm{H}$ bond cleavage is facilitated $[16,26]$. This mechanism is in agreement with the maximum catalytic activity found for $\theta_{T l} \approx 0.76$, since for this coverage the number of Pt-Tl ensembles, which are the catalytic active site, are maximized [13].

It is important to highlight that these results are different from those reported previously [20] by our research group. Such a difference is attributed to the stability of the $\mathrm{Tl}$ adlayer on the electrode surface. In the previous experiments, after modifying the electrode, and before being immersed into the cell containing formic acid, the electrode was rinsed with ultrapure water. We have recently observed that this rinsing step gives rise to an important removal of the $\mathrm{Tl}$ adsorbed on the surface of the electrode. This fact is the reason for which, in the previous contribution [20], the enhanced activity displayed by the $\mathrm{Tl}$ modified surfaces is much lower than that reported in the present contribution. In this work, a special care has been taken in order to keep as stable as possible the coverage of $\mathrm{Tl}$ on the electrode. Thus, after modifying the electrode with $\mathrm{Tl}$ and testing it in the electrolytic solution, this was taken directly into the cell containing formic acid $0.1 \mathrm{M}$, avoiding the loss of $\mathrm{Tl}$ because of the rinsing step. In relation to stability issues, it is also important to mention that, under the current electrochemical working conditions, the stability of the $\mathrm{Tl}$ adatoms is also low, particularly during the formic acid electrooxidation experiments in which a clear diminution of the activity is observed during the consecutive cycling experiments.

Figure 5 shows a normalization of the current density $\left(j_{\theta_{T l}} / j_{B a r e}\right)$ at the coverage where the maximum current is reached for each of the electrodes (black and red curves). It is clear from the figure that the "improvement factor" for the case of $\operatorname{Pt}(100)$ modified by $\mathrm{Tl}$ is bigger than that shown for $\mathrm{Tl}-\mathrm{Pt}(111)$, except for potentials below $0.3 \mathrm{~V}$, where 
$\operatorname{Tl}-\operatorname{Pt}(111)$ has a better improvement than $\mathrm{Tl}-\mathrm{Pt}(100)$. It is important to notice that the potential where $\mathrm{Tl}-\mathrm{Pt}(111)$ reach the maximum improvement factor is lower $(0.25 \mathrm{~V})$ compared with $0.35 \mathrm{~V}$ which is the potential at the maximum improvement in the case of $\mathrm{Tl}-\mathrm{Pt}(100)$.

As a conclusion, since $\mathrm{CO}$ adsorption from formic acid has specific Pt free sites requirements [27, 28], Tl adsorbed on $\mathrm{Pt}(100)$ has a positive effect because it enables preventing the $\mathrm{CO}$ formation (third body effect), whereas in the case of $\operatorname{Pt}(111)$ (which is an ideally poisoning resistant surface[14]), the main effect involves lowering the activation energy possibly by promoting the adsorption of the active intermediate in a configuration which facilitate the oxidation into $\mathrm{CO}_{2}$, similar with those effect described for Bi adatom previously [16, 26].

\subsection{FAOR on Tl modified Pt(s)[n(100)x(111)]}

Figures $6 \mathrm{~A}, 6 \mathrm{C}$ and $6 \mathrm{E}$ show the voltammetric profile for some electrodes belonging to the series $\operatorname{Pt}(s)[n(100) x(111)]$, that is, surfaces with (100) terraces and (111) steps, for increasing $\mathrm{Tl}$ coverages. In all the cases, as is observed for the $\mathrm{Pt}(100)$ electrode, the hydrogen adsorption/desorption region decreases as the $\mathrm{Tl}$ coverage increases. Additionally, a small peak around $0.17 \mathrm{~V}$ can be again observed in the

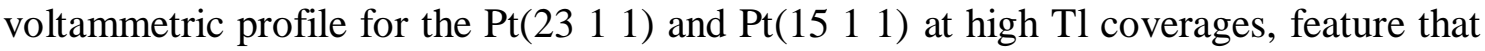
disappears for $\operatorname{Pt}(711)$ electrode. This fact suggests that long-range (100) domains are required to form those structures leading to the appearance of this particular feature. Another interesting point is that associated with the selective adsorption of the $\mathrm{Tl}$ adatom. For $\mathrm{Pt}(711)$, it is observed that $\mathrm{Tl}$ is adsorbed in the steps prior to the terraces, according to the Smoluchowski for electropositive adatoms [29]. This effect is not 
observed for the surfaces with longer terraces, similarly to what has been observed for this series of surfaces with bismuth [30]. It is important to highlight that the later behavior could be interesting to be applied in futures works to combine two types of adatoms in a stepped modified surface. For instance, modifying the steps with $\mathrm{Tl}$ adatom to suppress the poison formation combined with the modification with another adatom to promote the formic acid oxidation by the direct pathway.

Figures $6 \mathrm{~B}, 6 \mathrm{D}$ and $6 \mathrm{~F}$ show the activity for those $\mathrm{Tl}$ modified Pt electrodes towards formic acid oxidation. For $\operatorname{Pt}(231$ 1), that is, a surface still having wide (100) terraces, the maximum activity is achieved at coverage values about $\theta_{T l} \approx 0.30-0.40$, in good agreement with the case of $\mathrm{Pt}(100)$. Again, when the coverage becomes maximum, the activity decreases and the reaction is less favored, shifting the onset potential of the oxidation to more positive values. For the case of $\operatorname{Pt}\left(\begin{array}{lll}15 & 1 & 1\end{array}\right)$ and $\operatorname{Pt}(711)$ the response is clearly different to that previously shown and the activity systematically improves as the $\mathrm{Tl}$ coverage increases, being maximum at higher values. This behavior is quite similar to that observed previously for (100)-Pt NPs modified by $\mathrm{Tl}$, in which at maximum coverage was found the higher activity towards formic acid oxidation [20]. This fact points out the similitude between a shaped controlled nanoparticles and a stepped electrode in terms of surface structure and would suggest that the $\mathrm{Tl}$ has a positive effect in the electrocatalysis of formic acid through the direct pathway, as happens for the $\operatorname{Pt}(111)$ electrode.

Comparing the activities at $\theta_{T l}=0.33 \sim 0.36$ (figure 7), it can be seen that the current density decreases when the step density increases. This suggests that the surface arrangement reached in long-ranges (100) terraces is more effective to catalyze the reaction by the direct pathway. It is also important to point out that $\mathrm{CO}$ forms easily in 
step sites, independently of its crystallographic orientation [31, 32], which explains the lower activity when the terraces become shorter. Although the presence of steps in (100) terraces has minor effects on the modification of electrochemical properties than that one found for stepped $\operatorname{Pt}(111)$ surfaces [33], however, these changes are magnified with the modification by an adatom.

\subsection{FAOR on Tl modified Pt(s)[n(111)x(100)]}

Figure 8 reports the evolution of electrodes belonging to the series $\operatorname{Pt}(s)[n(111) x(100)]$, namely, $\operatorname{Pt}(1110$ 10) and Pt(544), after being modified with $\mathrm{Tl}$. The results obtained again show a decrease in all signals corresponding to the hydrogen and anion adsorption/desorption process, as the $\mathrm{Tl}$ coverage increases. The small peak centered around $0.45 \mathrm{~V}$ (associated to sulfate/bisulfate order transition) is presented in long (111) terraces stepped surfaces, being lost in Pt(544) electrode (see Figure $8 \mathrm{~A}$ and C).

Figures 8B and 8D display the corresponding formic acid electrooxidation activity. The results show that, for increasing $\mathrm{Tl}$ coverages, the oxidation current increases and the oxidation onset potential shifts the lower potential values, although these effects are less significant than that obtained with $\mathrm{Pt}(100)$ and its vicinal surfaces. Interestingly, the voltammetry for each Pt bare electrode shows that the $\mathrm{CO}$ formation is hindering the FAOR by the direct pathway, because of the smaller current density in the positive sweep compared with the negative one, being responsible for the hysteresis observed. When modifying the electrode with $\mathrm{Tl}$, the enhancement is quite similar for both electrodes. The only notorious difference is evidenced in the hysteresis between the positive and negative voltammetric cycles. For $\operatorname{Pt}\left(\begin{array}{lll}1 & 10 & 10\end{array}\right)$ the hysteresis is lost almost completely at $\theta_{T l} \cong 0.60$ (which could be considered as a high coverage). On the other 
hand, for $\operatorname{Pt}(544)$, even the positive sweep is higher than the negative one, suggesting that the insertion of a bigger stepped density, i.e. make it the (111) terraces shorter, favouring those adsorbed structures that prevent the $\mathrm{CO}$ formation, leading such an unusual "inverse" hysteresis effect at Pt(544) electrode.

\subsection{In situ FTIR experiments on Pt(100) and Pt(111)}

From the previous voltammetric experiments, it is evident that the incorporation of $\mathrm{Tl}$ is directly related to the suppression of the $\mathrm{CO}$ formation. However, to deepen on this aspect, some spectroscopic evidences (in situ FTIR experiments) will strongly contribute to elucidate the role played by the Tl adatom during FAOR [23]. In this regard, it is worth noting that during the in situ FTIR experiments, the formic acid concentration was diminished with the aim of decreasing the huge amount of $\mathrm{CO}_{2}$ formed during the experiment, which importantly destabilizes the thin-layer configuration. In addition, sulfuric acid concentration was reduced in order to avoid possible damage in the $\mathrm{CaF}_{2}$ prism due to the higher acid concentrations.

Figure 9 shows some selected spectra obtained with $\mathrm{Tl}$ modified and unmodified $\operatorname{Pt}(100)$ and $\operatorname{Pt}(111)$ surfaces. For bare $\operatorname{Pt}(100)$ and $\operatorname{Pt}(111)$, it is clear the presence of $\mathrm{CO}$ adsorbed on the electrode surface in both linear and bridge configuration (for $\operatorname{Pt}(111)$ electrode only linear CO is present) at $2030-2070 \mathrm{~cm}^{-1}$ and $1840-1870 \mathrm{~cm}^{-1}$, respectively [34-36]. It is worthy to clarify that the presence of $\mathrm{CO}$ adsorbed on $\mathrm{Pt}(111)$ is due to the presence of some defects on the electrode used to carry out these experiments. These bands are clearly present even at $0.5 \mathrm{~V}$ where the incipient $\mathrm{CO}$ oxidation takes place. Consequently, at $0.4 \mathrm{~V}$, the formation of $\mathrm{CO}_{2}$ starts for both electrodes, as deduced from the band at $2340 \mathrm{~cm}^{-1}$. When the electrodes are modified by 
$\mathrm{Tl}$ (at maximum coverage), the $\mathrm{CO}$ band is absent and the $\mathrm{CO}_{2}$ band is observed at very low potentials (even before $0.1 \mathrm{~V}$ ).

Similar in situ FTIR experiments were also performed with the $\operatorname{Pt}(\operatorname{s})[n(111) x(100)]$ electrodes. For the sake of comparison, figure 10 shows the integration of the $\mathrm{CO}_{2}$ band normalized to the same integrated $\mathrm{CO}_{2}$ band at $0.8 \mathrm{~V}$ for each experiment. At $0.1 \mathrm{~V}$, it is observed that the $\operatorname{Pt}(711)$ displays the highest ratio, thus indicating the positive contribution of the (111) steps for this reaction. In fact, in figure 7, can be seen that the onset of the oxidation is the lowest compared with the other stepped surfaces. Interestingly, for the three electrodes studied, an almost complete $\mathrm{CO}_{2}$ formation/production (90\%) is reached at a potential about $0.2 \mathrm{~V}$ regardless the electrode employed. These results confirm the third body effect played by the $\mathrm{Tl}$ in the modified electrode [13].

\section{Conclusions}

A systematic FAOR study on Pt single crystal electrodes modified by Tl has been done. Voltammetric experiments in $\operatorname{Pt}(100)$ and vicinal surfaces, $\operatorname{Pt}(s)[(100) x(111)]$, modified by $\mathrm{Tl}$ present an important enhancement towards formic acid oxidation, lowering the onset potential of oxidation and increasing the current density in the positive sweep voltammetry. For $\mathrm{Pt}(111)$, the main effect of $\mathrm{Tl}$ is notorious in the diminution of the onset potential of the oxidation, as well as the lowering in the potential where the current density reach maximum values, demonstrating a bifunctional effect of the $\mathrm{Tl}$ adatom, through the diminution of the activation energy of the reaction. On the other hand, for $\operatorname{Pt}(s)[(111) x(100)]$ stepped surfaces, was found that $\mathrm{Tl}$ modification reduce the hysteresis between positive and negative cycle, whereas the 
activity in the whole potential range is also improved. Although there is an important improvement in both, $\mathrm{Pt}(111)$ and $\mathrm{Pt}(100)$ electrodes modified by $\mathrm{Tl}$, the enhancement is more significant in the case of $\operatorname{Pt}(100)$

In situ FTIR experiments show that $\mathrm{CO}$ band disappear completely when $\mathrm{Pt}(100)$ and $\mathrm{Pt}(111)$ have been modified by $\mathrm{Tl}$ adatom, leading $\mathrm{CO}_{2}$ production at lower potentials (even at $0.1 \mathrm{~V}$ ). By combining voltammetric and spectroscopic data it can be concluded that $\mathrm{Tl}$ presents a third body effect for the formation of $\mathrm{CO}$. Its role can be summarized as follow: when modifying $\mathrm{Pt}(100)$ and its vicinal surfaces with $\mathrm{Tl}$, the indirect pathway ( $\mathrm{CO}$ adsorption) is hindered by the arrangement of $\mathrm{Tl}$ on the electrode surface. The diminution of the onset potential for the oxidation also indicates that $\mathrm{Tl}$ is , promoting formic acid oxidation through the direct pathway through bifunctional effect, leading a similar behavior to that found for Bi-Pt previously.

\section{Acknowledgments}

This work has been financially supported by the MINECO (Spain) (projects CTQ2013-44083-P and CTQ2013-48280-C3-3-R) and Generalitat Valenciana (project PROMETEOII/2014/013, FEDER).

\section{References}

[1] J.M. Feliu, E. Herrero, Formic acid oxidation, in: W. Vielstich, H. Gasteiger, A. Lamm (Eds.) Handbook of Fuel Cells - Fundamentals, Technology and Applications, John Wiley \& Sons, Ltd., Chichester, 2003, pp. 625-634.

[2] M.T.M. Koper, Fuel Cell Catalysis: A Surface Science Approach, John Wiley \& Sons, Hoboken, New Jersey, 2009.

[3] C. Rice, R.I. Ha, R.I. Masel, P. Waszczuk, A. Wieckowski, T. Barnard, Direct formic acid fuel cells, J. Power Sources, 111 (2002) 83-89. 
[4] C. Rice, S. Ha, R.I. Masel, A. Wieckowski, Catalysts for direct formic acid fuel cells, J. Power Sources, 115 (2003) 229-235.

[5] J.V. Perales-Rondon, E. Herrero, J.M. Feliu, Effects of the anion adsorption and pH on the formic acid oxidation reaction on $\mathrm{Pt}(111)$ electrodes, Electrochim. Acta, 140 (2014) 511-517.

[6] H.-F. Wang, Z.-P. Liu, Formic Acid Oxidation at Pt/H2O Interface from Periodic DFT Calculations Integrated with a Continuum Solvation Model, J. Phys. Chem. C, 113 (2009) 17502-17508.

[7] V. Grozovski, V. Climent, E. Herrero, J.M. Feliu, Intrinsic Activity and Poisoning Rate for $\mathrm{HCOOH}$ Oxidation at $\mathrm{Pt}(100)$ and Vicinal Surfaces Containing Monoatomic (111) Steps, ChemPhysChem, 10 (2009) 1922-1926.

[8] V. Grozovski, V. Climent, E. Herrero, J.M. Feliu, Intrinsic activity and poisoning rate for $\mathrm{HCOOH}$ oxidation on platinum stepped surfaces, Phys. Chem. Chem. Phys., 12 (2010) 8822-8831.

[9] S.P.E. Smith, K.F. Ben-Dor, H.D. Abruna, Structural effects on the oxidation of $\mathrm{HCOOH}$ by bismuth-modified $\mathrm{Pt}(111)$ electrodes with (100) monatomic steps, Langmuir, 15 (1999) 7325-7332.

[10] Y.-Y. Yang, S.-G. Sun, Y.-J. Gu, Z.-Y. Zhou, C.-H. Zhen, Surface modification and electrocatalytic properties of $\operatorname{Pt}(100), \operatorname{Pt}(110), \operatorname{Pt}(320)$ and $\operatorname{Pt}(331)$ electrodes with Sb towards HCOOH oxidation, Electrochim. Acta, 46 (2001) 4339-4348.

[11] A. Boronat-Gonzalez, E. Herrero, J.M. Feliu, Fundamental aspects of $\mathrm{HCOOH}$ oxidation at platinum single crystal surfaces with basal orientations and modified by irreversibly adsorbed adatoms, J. Solid State Electrochem., 18 (2014) 1181-1193.

[12] F.J. Vidal-Iglesias, J. Solla-Gullón, E. Herrero, A. Aldaz, J.M. Feliu, Formic acid oxidation on Pd-modified Pt(100) and Pt(111) electrodes: A DEMS study, J. Appl. Electrochem., 36 (2006) 1207-1214.

[13] E. Leiva, T. Iwasita, E. Herrero, J.M. Feliu, Effect of adatoms in the electrocatalysis of $\mathrm{HCOOH}$ oxidation. A theoretical model, Langmuir, 13 (1997) 62876293.

[14] E. Herrero, A. Fernández-Vega, J.M. Feliu, A. Aldaz, Poison formation reaction from formic acid and methanol on $\mathrm{Pt}(111)$ electrodes modified by irreversibly adsorbed Bi and As J. Electroanal. Chem., 350 (1993) 73-88.

[15] M. Shibata, N. Furuya, M. Watanabe, S. Motoo, Electrocatalysis by ad-atoms. Part XXIV. Effect of arrangement of Bi ad-atoms on formic acid oxidation, J. Electroanal. Chem., 263 (1989) 97-108.

[16] J.V. Perales-Rondon, A. Ferre-Vilaplana, J.M. Feliu, E. Herrero, Oxidation Mechanism of Formic Acid on the Bismuth Adatom-Modified Pt(111) Surface, J. Am. Chem. Soc., 136 (2014) 13110-13113. 
[17] J. Clavilier, J.P. Ganon, M. Petit, A comparative study of the underpotential deposition of two monovalent cations, $\mathrm{Tl}^{+}$and $\mathrm{H}^{+}$, on $\mathrm{Pt}(111)$ as a way to the interpretation of the unusual adsorption states, J. Electroanal. Chem., 265 (1989) 231245.

[18] P. Rodriguez, N. García-Aráez, E. Herrero, J.M. Feliu, New insight on the behavior of the irreversible adsorption and underpotential deposition of thallium on platinum (111) and vicinal surfaces in acid electrolytes, Electrochim. Acta, 151 (2015) 319-325.

[19] T. Hartung, J. Willsau, J. Heitbaum, Catalytic effects of Hg and Tl submonolayers on the electrooxidation of formic acid on Pt, J. Electroanal. Chem., 205 (1986) 135-149.

[20] C. Buso-Rogero, J.V. Perales-Rondon, M.J.S. Farias, F.J. Vidal-Iglesias, J. SollaGullon, E. Herrero, J.M. Feliu, Formic acid electrooxidation on thallium-decorated shape-controlled platinum nanoparticles: an improvement in electrocatalytic activity, Phys. Chem. Chem. Phys., 16 (2014) 13616-13624.

[21] J. Clavilier, D. Armand, S.G. Sun, M. Petit, Electrochemical adsorption behaviour of platinum stepped surfaces in sulphuric acid solutions J. Electroanal. Chem., 205 (1986) 267-277.

[22] J. Clavilier, K. El Achi, M. Petit, A. Rodes, M.A. Zamakhchari, Electrochemical monitoring of the thermal reordering of platinum single crystal surfaces after metallographic polishing from the early stage to the equilibrium surfaces, J. Electroanal. Chem., 295 (1990) 333.

[23] T. Iwasita, F.C. Nart, In situ infrared spectroscopy at electrochemical interfaces, Prog. Surf. Sci., 55 (1997) 271-340.

[24] R.R. Adzic, J.X. Wang, O.M. Magnussen, B.M. Ocko, Structure of Tl adlayers on the $\mathrm{Pt}(111)$ electrode surface: Effects of solution $\mathrm{pH}$ and bisulfate coadsorption, J. Phys. Chem., 100 (1996) 14721-14725.

[25] J. Clavilier, S.G. Sun, Electrochemical Study of the Chemisorbed Species Formed from Formic-Acid Dissociation at Platinum Single-Crystal Electrodes, J. Electroanal. Chem., 199 (1986) 471-480.

[26] A. Ferre-Vilaplana, J.V. Perales-Rondon, J.M. Feliu, E. Herrero, Understanding the Effect of the Adatoms in the Formic Acid Oxidation Mechanism on Pt(111) Electrodes, ACS Catal., 5 (2015) 645-654.

[27] M.J. Llorca, E. Herrero, J.M. Feliu, A. Aldaz, Formic acid oxidation on Pt(111) electrodes modified by irreversibly adsorbed selenium, J. Electroanal. Chem., 373 (1994) 217-225.

[28] S.C. Chang, Y. Ho, M.J. Weaver, Applications of real-time infrared spectroscopy to electrocatalysis at bimetallic surfaces. I. Electrooxidation of formic acid and methanol on bismuth-modified Pt(111) and Pt(100), Surf. Sci., 265 (1992) 81-94.

[29] E. Herrero, V. Climent, J.M. Feliu, On the different adsorption behavior of bismuth, sulfur, selenium and tellurium on a $\operatorname{Pt}(775)$ stepped surface, Electrochem. Commun., 2 (2000) 636-640. 
[30] R. Gisbert, V. Climent, E. Herrero, J.M. Feliu, Underpotential Deposition of Copper on $\mathrm{Pt}(\mathrm{S})[\mathrm{n}(100) \times(110)]$ Stepped Surfaces, Journal of Electrochemistry, 18 (2012) 410-426.

[31] M.D. Maciá, E. Herrero, J.M. Feliu, A. Aldaz, Formic acid self-poisoning on bismuth-modified stepped electrodes, J. Electroanal. Chem., 500 (2001) 498-509.

[32] M.D. Maciá, E. Herrero, J.M. Feliu, A. Aldaz, Formic acid self-poisoning on bismuth-modified Pt(755) and Pt(775) electrodes, Electrochem. Commun., 1 (1999) 8789.

[33] A. Ferre-Vilaplana, R. Gisbert, E. Herrero, On the electrochemical properties of platinum stepped surfaces vicinal to the (100) pole. A computational study, Electrochim. Acta, 125 (2014) 666-673.

[34] K. Kunimatsu, Infrared spectroscopic study of methanol and formic acid adsorbates on a platinum electrode: Part I. Comparison of the infrared absorption intensities of linear $\mathrm{CO}$ (a) derived from $\mathrm{CO}, \mathrm{CH}_{3} \mathrm{OH}$ and $\mathrm{HCOOH}$ J. Electroanal. Chem., 213 (1986) 149-157.

[35] K. Kunimatsu, H. Seki, W.G. Golden, J.G. Gordon, M.R. Philpott, Carbon monoxide adsorption on a platinum electrode studied by polarization modulated FTIR reflection-absorption spectroscopy. 2.CO adsorbed at a potential in the hydrogen region and its oxidation in acids, Langmuir, 2 (1986) 464.

[36] S.G. Sun, J. Clavilier, A. Bewick, The mechanism of electrocatalytic oxidation of formic acid on Pt (100) and Pt (111) in sulphuric acid solution: an emirs study, J. Electroanal. Chem., 240 (1988) 147-159. 


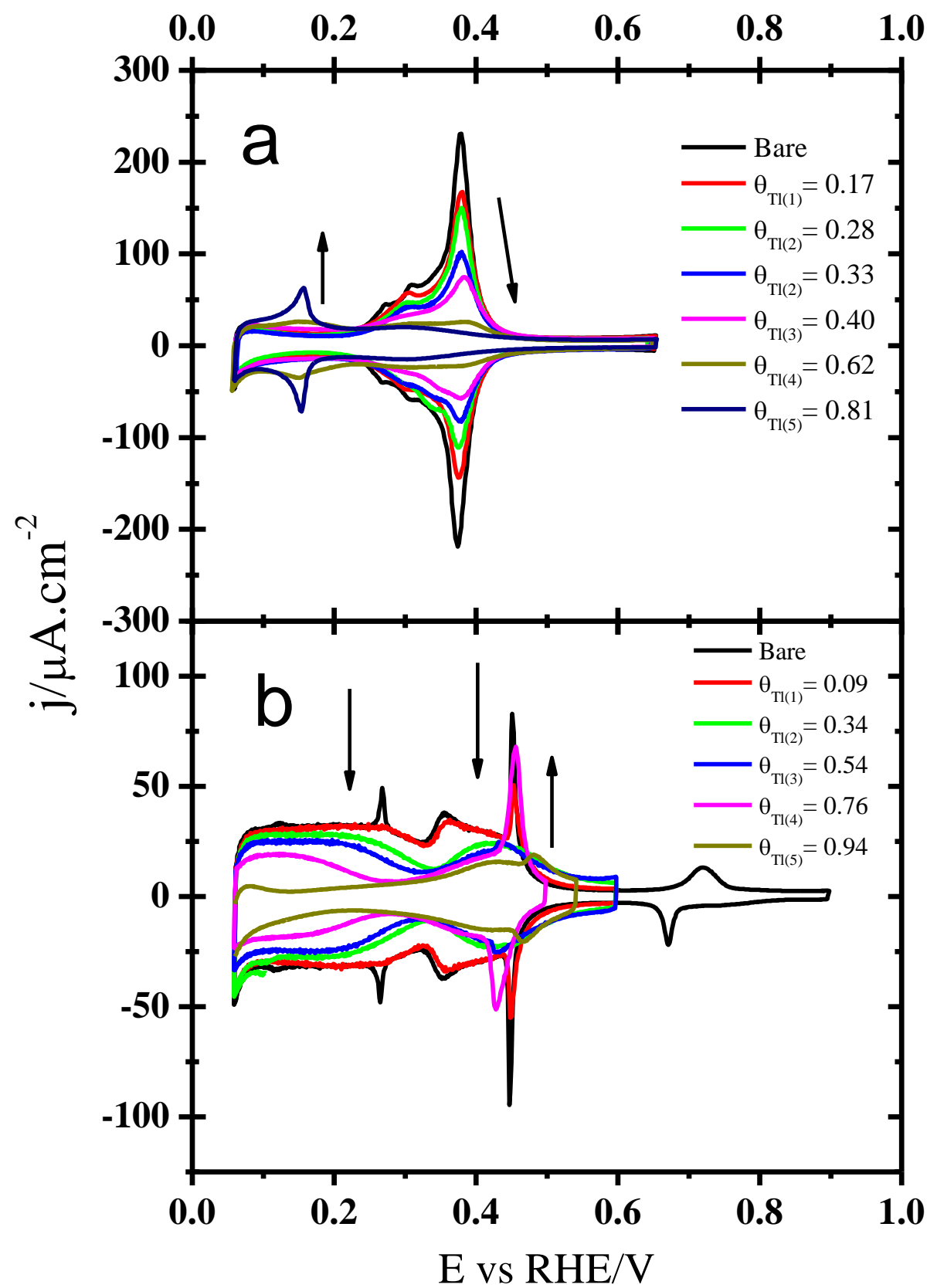

Figure 1. Cyclic voltammetry of $\mathrm{Tl}$ modified Pt single crystal electrodes taken in $\mathrm{H}_{2} \mathrm{SO}_{4} 0.5 \mathrm{M}$ at different $\mathrm{Tl}$ coverages. (a) $\mathrm{Tl}$ modified $\mathrm{Pt}(100)$ electrode; (b) $\mathrm{Tl}$ modified $\mathrm{Pt}(111)$ electrode. Scan rate $50 \mathrm{mV} . \mathrm{s}^{-1}$. 


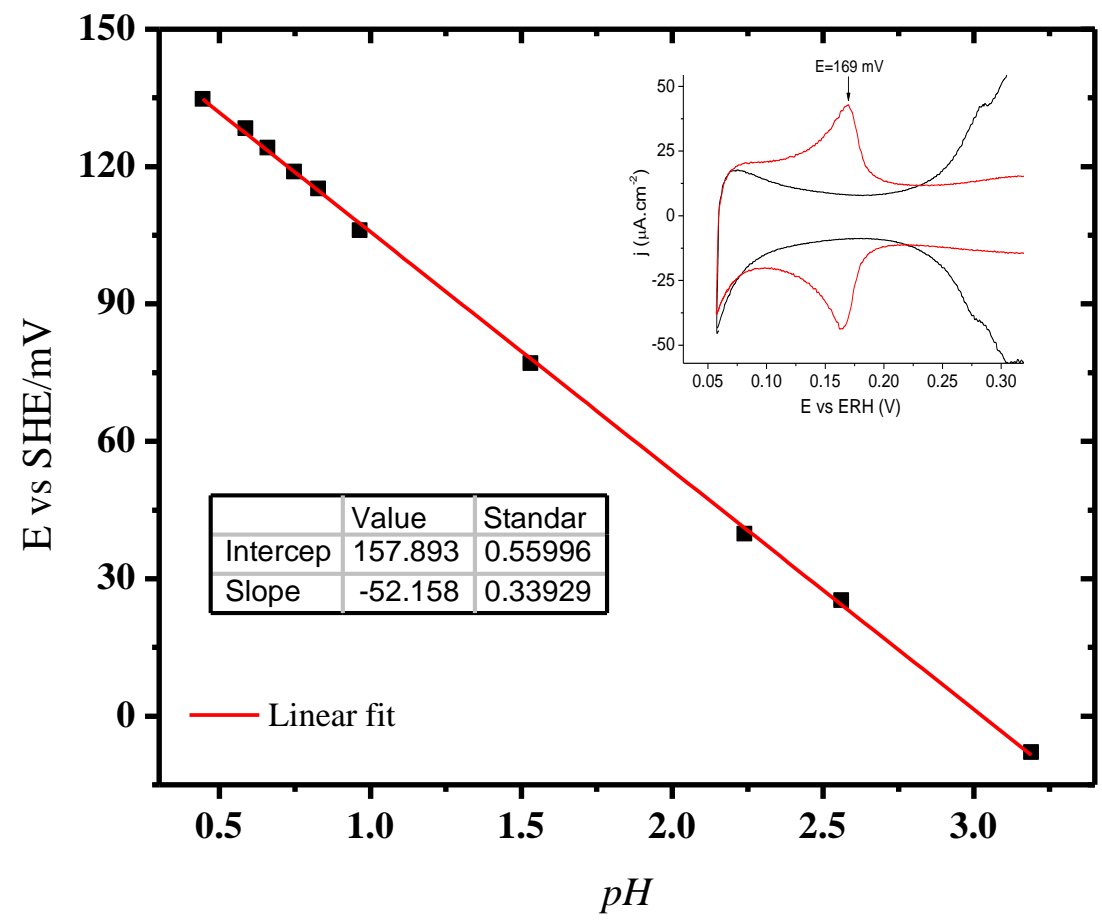

Figure 2. Linear relationship between the peak potential of the reversible feature in $\mathrm{Tl}$ modified $\mathrm{Pt}(100)$ electrode (inset) and the solution $\mathrm{pH}$. 


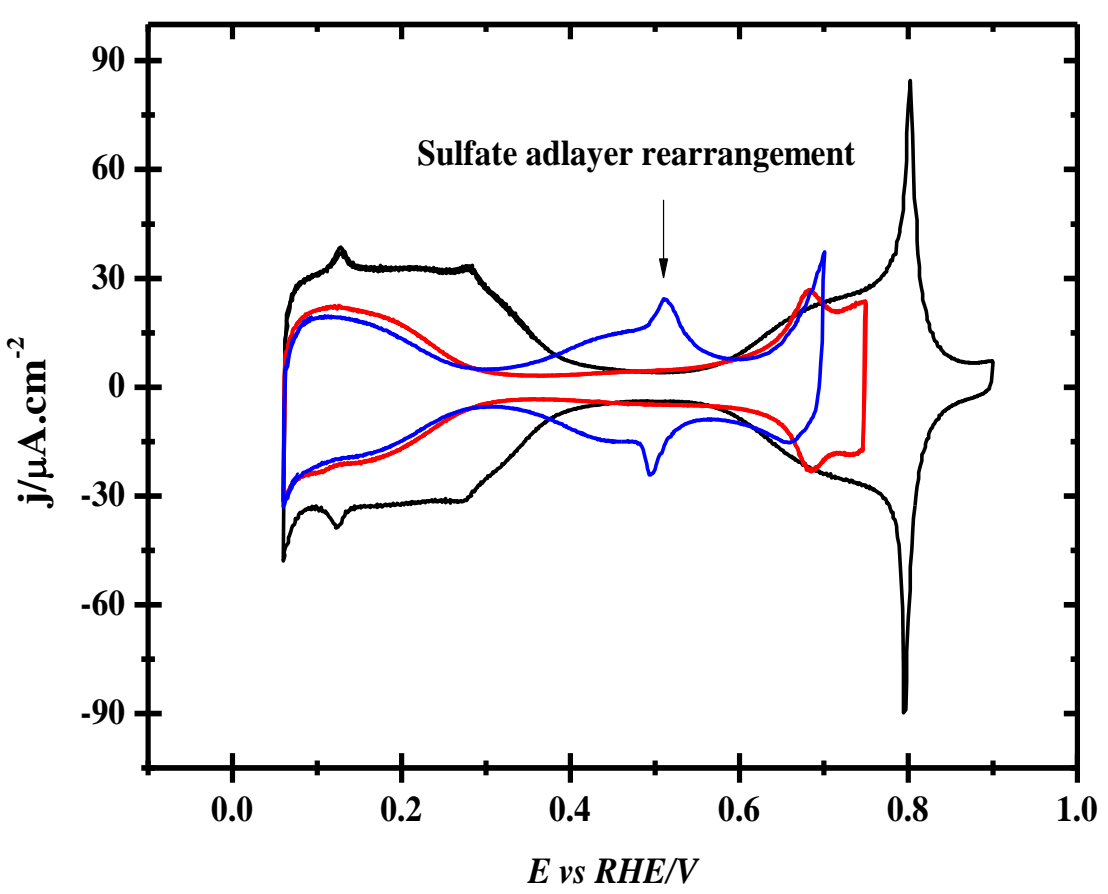

Figure 3. Comparison between voltammetric profile of the $\mathrm{Pt}(111)$ modified by $\mathrm{Tl}$ adatom in: perchloric acid (red line) and perchloric acid with sulfate anions (blue line). The black line represents the voltammetric profile for the blank in perchloric acid. Scan rate: $0.05 \mathrm{~V} \mathrm{~s}^{-1}$ 


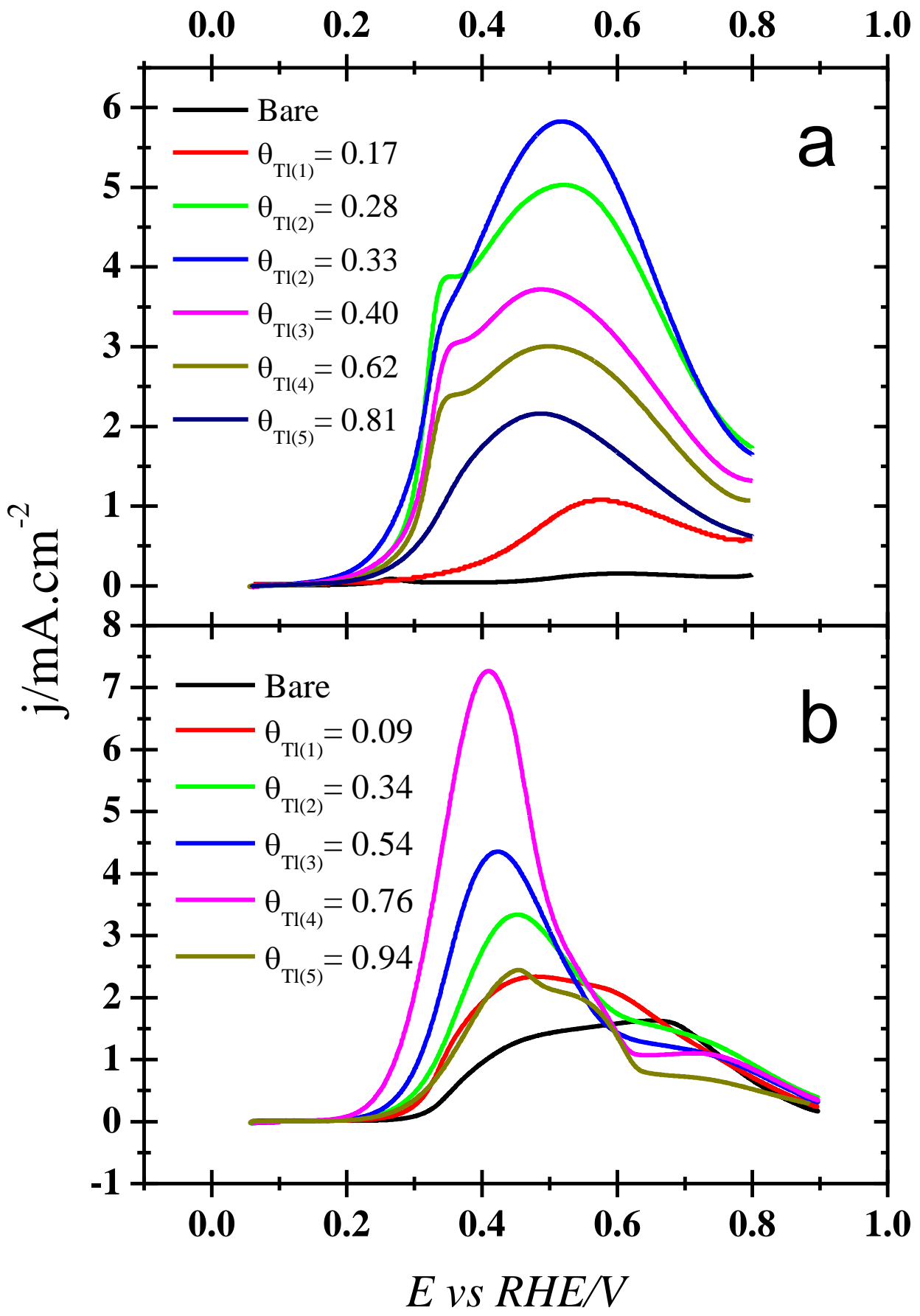

Figure 4. Positive sweep voltammetry for $0.1 \mathrm{M} \mathrm{HCOOH}$ oxidation in $\mathrm{H}_{2} \mathrm{SO}_{4} 0.5 \mathrm{M}$ for: (a) $\mathrm{Tl}$ modified $\mathrm{Pt}(100)$ and (b) Tl modified $\mathrm{Pt}(111)$ single crystal electrodes. Scan rate $0.02 \mathrm{~V} \mathrm{~s}^{-1}$. 


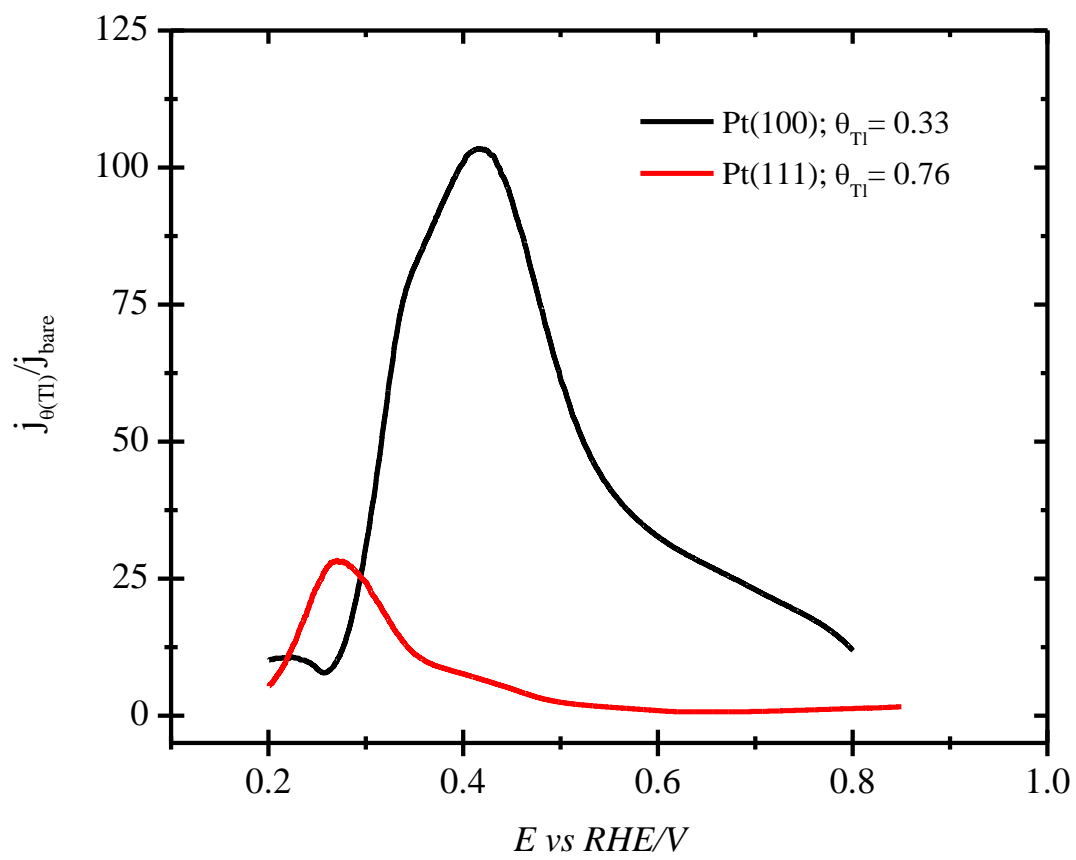

Figure 5. FAOR current densities normalized using the bare and $\mathrm{Tl}$-modified $\mathrm{Pt}(100)$ (black line) and $\operatorname{Pt}(111)$ (red line). Data taken from figure 4. 


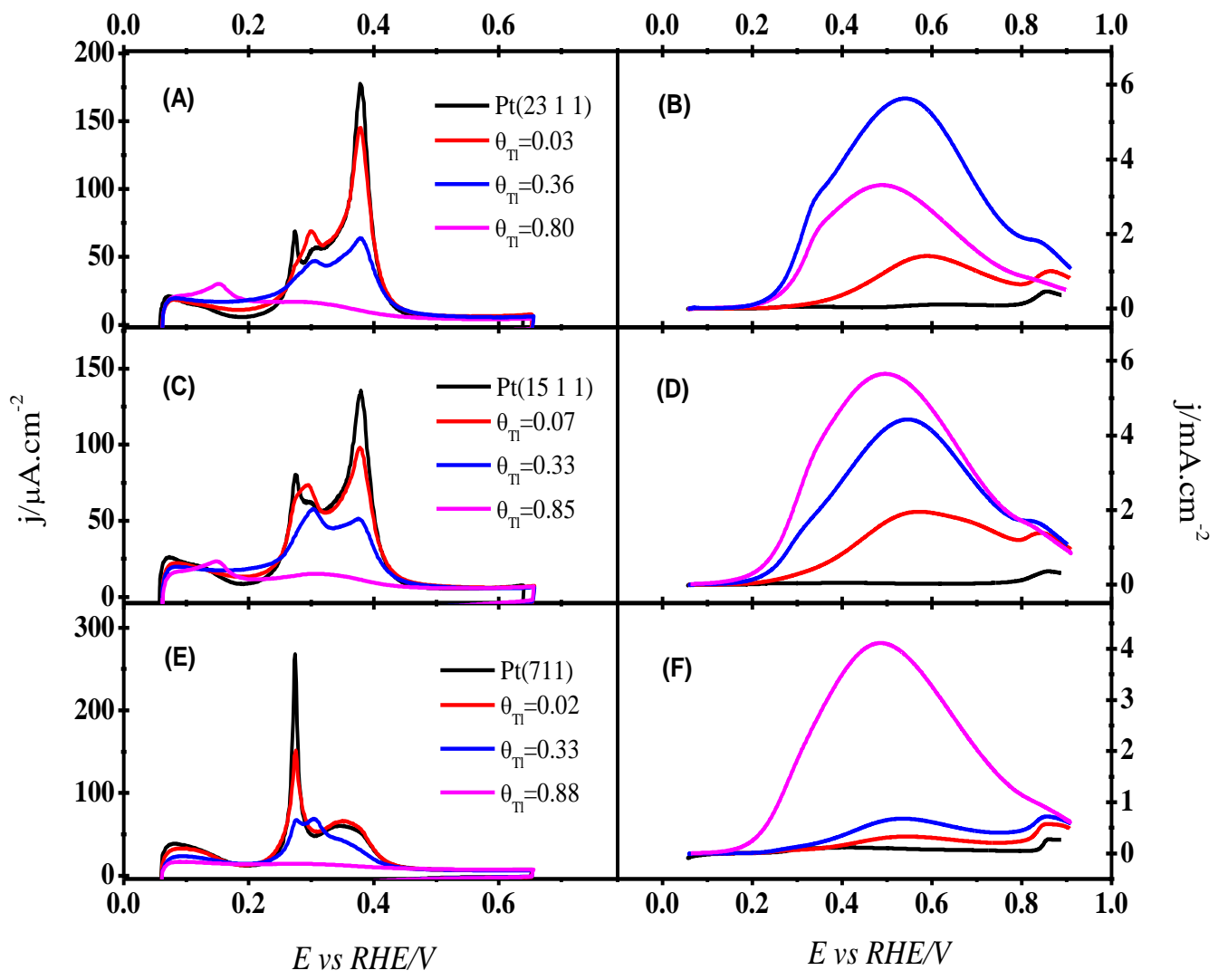

Figure 6. Positive sweep voltammetryfor: (A) Tl modified Pt(23 1 1); (C) Tl modified $\mathrm{Pt}\left(\begin{array}{l}15 \\ 1\end{array}\right.$ 1) and (E) Tl modified $\mathrm{Pt}(711)$ single crystal electrodes in $\mathrm{H}_{2} \mathrm{SO}_{4}$ 0.5 M. Scan rate $0.05 \mathrm{~V} \mathrm{~s}^{-1}$. Positive sweep voltammetry for: (B) Tl modified $\mathrm{Pt}(2311$ ); (D) Tl modified $\mathrm{Pt}\left(\begin{array}{l}15 \\ 1\end{array} 1\right)$ and $(\mathrm{F}) \mathrm{Tl}$ modified $\mathrm{Pt}(711)$ single crystal electrodes in $0.1 \mathrm{M}$ $\mathrm{HCOOH}+\mathrm{H}_{2} \mathrm{SO}_{4} 0.5 \mathrm{M}$. Scan rate $0.02 \mathrm{~V} \mathrm{~s}^{-1}$. 


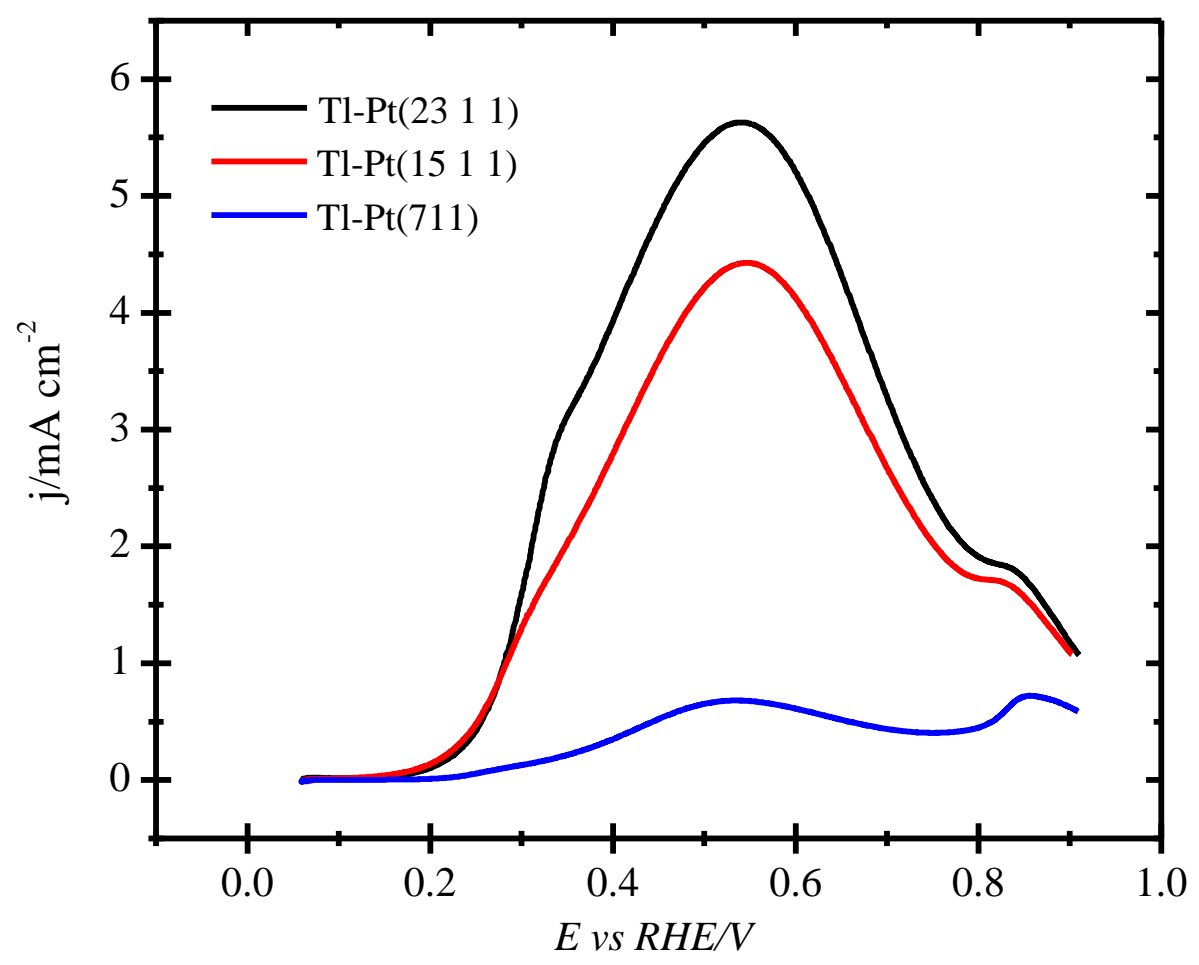

Figure 7. Comparison of the positive sweep for formic acid oxidation on $\mathrm{Tl}$ modified $\mathrm{Pt}$ single crystal belonging to the series $\operatorname{Pt}(\operatorname{s})[n(100) x(111)]$ at a coverage $\theta_{T l}=$ $0.33 \sim 0.36$. Values taken from figure 6. 


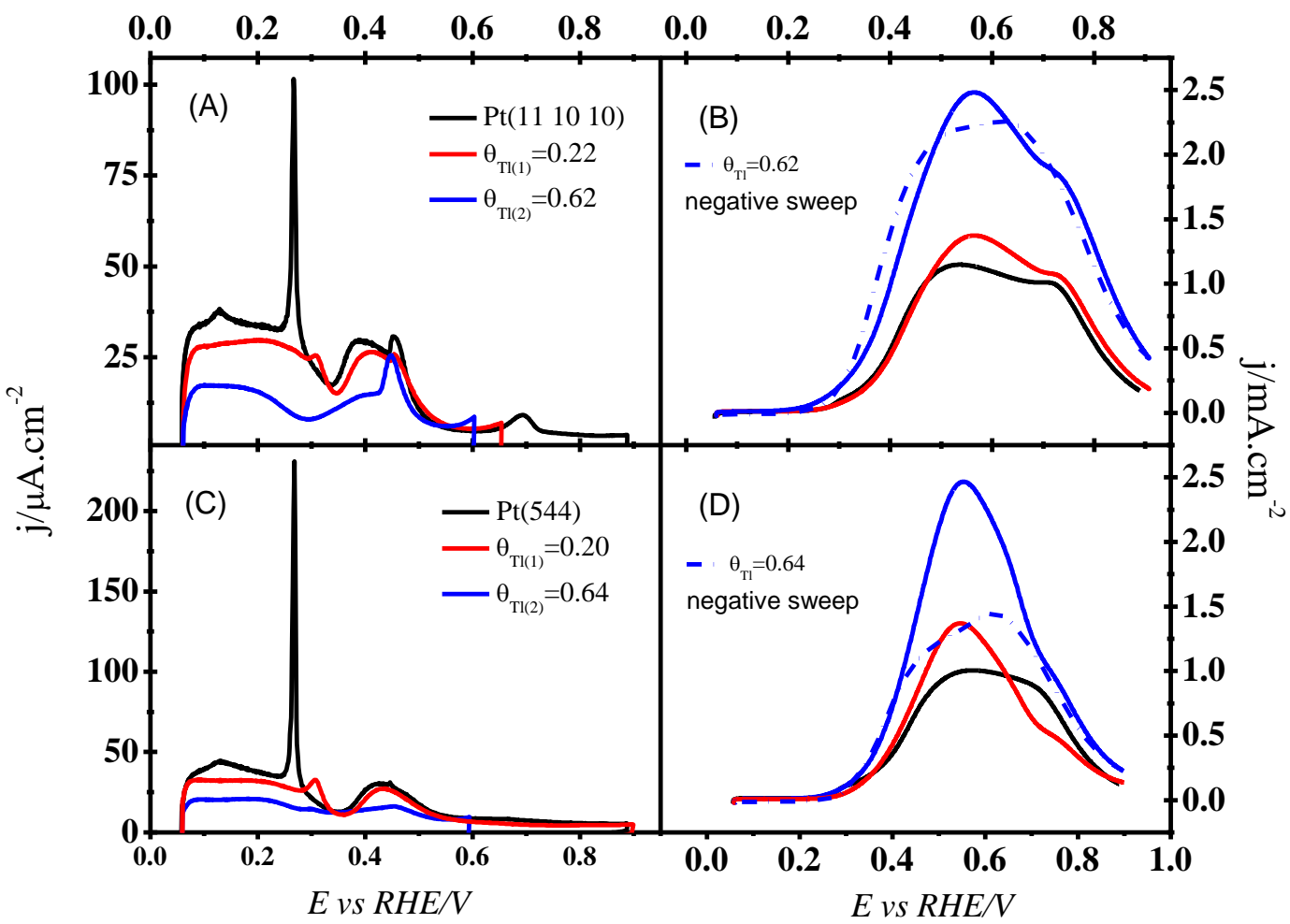

Figure 8. Positive sweep voltammetryfor: (A) Tl modified $\mathrm{Pt}(1110$ 10) and (C) $\mathrm{Tl}$ modified $\mathrm{Pt}(544)$ single crystal electrodes in $\mathrm{H}_{2} \mathrm{SO}_{4} 0.5 \mathrm{M}$. Scan rate $0.05 \mathrm{~V} \mathrm{~s}^{-1}$. .

Positive sweep voltammetry in $\mathrm{H}_{2} \mathrm{SO}_{4} 0.5 \mathrm{M}$ for: (B) Tl modified $\mathrm{Pt}(1110$ 10) and (D) Tl modified $\mathrm{Pt}(544)$ single crystal electrodes in $0.1 \mathrm{M} \mathrm{HCOOH}+\mathrm{H}_{2} \mathrm{SO}_{4} 0.5 \mathrm{M}$. Scan rate $0.02 \mathrm{~V} \mathrm{~s}^{-1}$. 


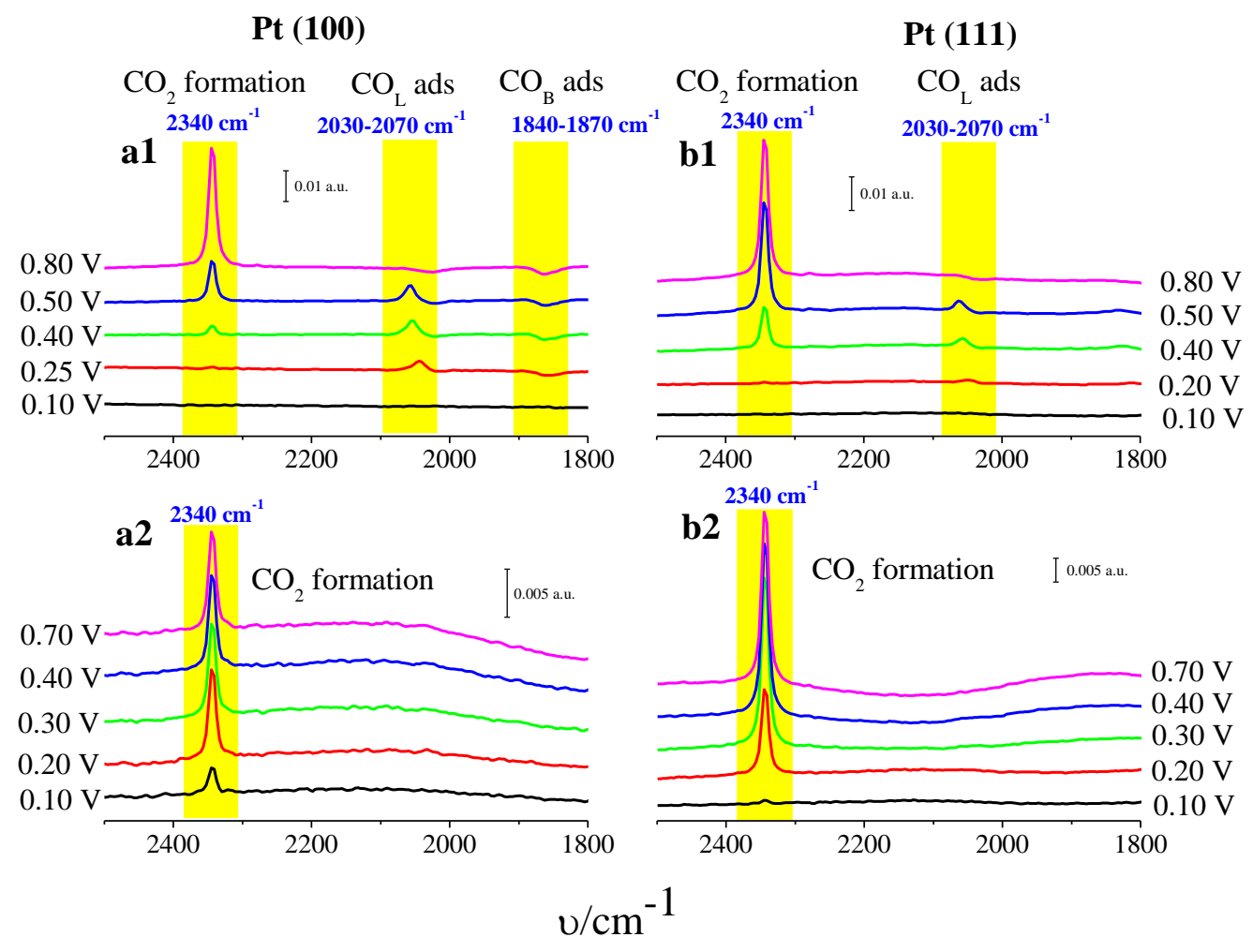

Figure 9. In situ FTIR experiments in $0.05 \mathrm{M} \mathrm{HCOOH}+0.1 \mathrm{M} \mathrm{H}_{2} \mathrm{SO}_{4}$ for: (a) $\mathrm{Pt}$ (100) and (b) Pt (111) electrode. Spectra denoted as ' 1 ' correspond to the bare Pt electrode whereas ' 2 ' indicates spectra collected in Pt electrodes modified with $\mathrm{Tl}$ at the maximum coverage. 


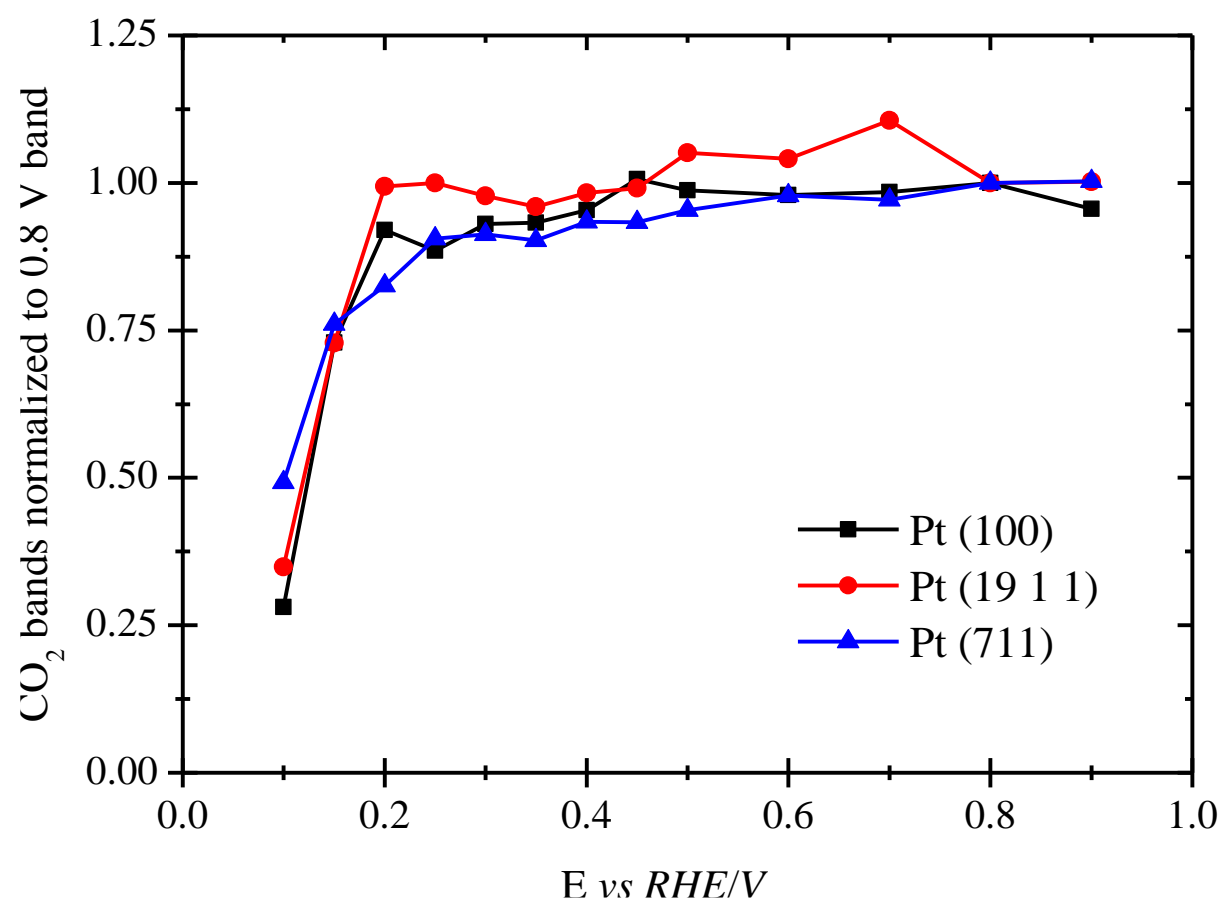

Figure 10. Ratio between integrated intensities of the $\mathrm{CO}_{2}$ bands and the integral of the same $\mathrm{CO}_{2}$ band at $0.8 \mathrm{~V}$ for the Tl-modified Pt electrodes at the maximum coverage at different potentials. 